\title{
THE MULTIROLE OF MODIFIED NATURAL GUMS FOR MULTICOMPONENT POLYMERS: AS COUPLING AGENTS FOR POLYMERS REINFORCED WITH CELLULOSIC FIBERS OR COMPATIBILIZERS FOR BIODEGRADABLE POLYMER BLENDS
}

\author{
Jorge D. Inga-Lafebrea, Héctor Pulido-Gonzáleza , Rubén González-Núñeza , María E. Hernández-Hernándeza, Martín \\ Rabelero-Velasco ${ }^{a}$, Francisco J. Aranda-García ${ }^{a}$ and Carlos F. Jasso-Gastinel*a \\ ${ }^{a}$ Chemical Engineering Department, Centro Universitario de Ciencias Exactas e Ingenierías, Universidad de Guadalajara, 44430 \\ Guadalajara - Jalisco, México
}

Recebido em 18/10/2018; aceito em 19/12/2018; publicado na web em 06/02/2019

\begin{abstract}
In this work, the capability to use pine rosin as a biodegradable coupling agent/compatibilizer is studied. To formulate composites, post-consumer polypropylene and discarded agave fibers (as reinforcing agent) are coupled with pine rosin (in pure or maleated form). Besides, poly(lactic acid) (PLA) with poly(butylene adipate-co-terephthalate) (PBAT) are compatibilized with maleated pine rosins to prepare biodegradable blends. For the coupling agent role, the pure or maleated rosin (Amberyl M-15A) are compared with a commercial polyolefin coupling agent (Epolene E-43), while for the blends, two maleated rosins (Amberyls M-15A and MP-30) are used as compatibilizers. Dynamic and static mechanical tests show considerable increments in moduli and strength for both types of polymeric materials surpassing the role of the Epolene E-43 for the composite materials (v.g. 45.2 vs 16.5 increment in storage modulus, or 61.5 vs 40.3 for Young's modulus in specific tests). Scanning electron microscopy photographs clearly show the interfacial interaction effect within composites and polymer blends. Fourier transform infrared spectroscopy allowed the observation of the aforementioned interactions at bond level. Blends biodegradation performed by composting for 3 months exceeded $76 \%$ of weight loss. The multirole of modified natural maleated gums as coupling agents/compatibilizers is demonstrated.
\end{abstract}

Keywords: biodegradable blend; composite, maleated resin; rosin; post-consumer.

\section{INTRODUCTION}

To achieve specific properties with multicomponent polymers that are ecologically friendly, there is a concern to recycle polymers for composites preparation and to develop biodegradable polymer blends. In both cases, due to the common incompatibility of the components, to accomplish or increase their interaction, the use of a coupling agent/compatibilizer is advisable. Considering possible resins for such applications, pine gums (which are from natural origin) are commonly used in paints, adhesives and the pharmaceutical industry, with the advantage of being biodegradable. ${ }^{1}$ As a novel application, Jasso et al., tested a pine gum in pure and maleated forms as coupling agents (CAs) for thermoplastic composites reinforced with natural fibers. From the positive results obtained with such gums as CAs compared to a commercial maleated polyolefin (Epolene E-43), a patent application was registered. ${ }^{2}$ For these reasons, in the first section of this work, natural or glyceromaleic rosin gum (Amberyl M-15A) is used here as CAs for post-consumer Polypropylene (PPr), reinforced with discarded agave fibers. Polypropylene (PP) has been chosen here because of its numerous industrial applications. ${ }^{3}$

For Polypropylene, it has been reported that significant changes in melt flow index and mechanical properties degradation occur with 5 reprocessing cycles. ${ }^{4,5}$ Nevertheless, high impact PP filled with talc showed more thermal and mechanical stability than its unfilled reprocessed form, using 3-12 reprocessing cycles. ${ }^{6}$ Searching for an improvement in another study, K. Das et al. tested two different types of commercial CAs for post-consumer PP reinforced with fly-ash (Si oxide based byproduct from thermal power plants); they obtained $15 \%$ in modulus and $9.5 \%$ in strength increments with a silane based coupling agent (Dynasylan VTMO); they reported the

*e-mail: carlos.jasso@cucei.udg.mx benefit of the chemical interaction between the Si oxide based filler and the silane coupling agent. ${ }^{7}$

Regarding ecological fillers, due to their useful characteristics, discarded natural fibers ${ }^{8}$ have been used in different fields of polymeric materials as reinforcing agents for decades.-14 However, the lack of interaction between hydrophobic polymers and cellulosic fibers makes fiber dispersion difficult during the mixing process. ${ }^{8}$ In that context, fiber modification ${ }^{15}$ and/or the use of different $C A s^{16}$ have been applied to promote interfacial adhesion between those components looking for industrial applications. The best results for polyolefins have been obtained with maleic anhydride, due to the chemical interaction based on hydrogen bonding or chemical linkages ${ }^{17}$ Based on those studies, some companies have developed commercial maleated synthetic polymers as CAs (e.g.: Eastman Chemical Corp., Saco AEI Polymers, Yparex Co.) to make different products in the field of wood-like composites. Such commercial CAs validate the use of maleated natural polymers like the ones used in this work, to improve mechanical properties of post-consumer polymers, to make composites for different applications in the aforementioned field.

Besides composites, for the production of biodegradable blends, poly(lactic acid) (PLA) which is a biobased polymer, ${ }^{18}$ is becoming popular for different kinds of applications, due to its competitive price compared to other biodegradable homopolymers; ${ }^{19,20}$ however, in spite of its high Young modulus, as it shows very low deformation capacity, it must be blended with other biodegradable polymers for some applications aiming for higher strain capability. Poly (butylene adipate-co-terephthalate), (PBAT), has been recently blended with PLA aiming for tough polymeric materials; nevertheless, since the PLA/PBAT blend shows immiscibility, its phase separation leads to a decrease in some material properties as a result of a poor interfacial adhesion between the components. ${ }^{21}$ In fact, it has been reported that mechanical properties improvement is not observed with more than $20-25$ wt $\%$ of PBAT in the blend, due to that immiscibility. ${ }^{22}$ In 
that situation, for the intended improvement in mechanical properties along with biodegradability, an 80/20 w/w PLA/PBAT blend is proposed in this work to be compatibilized with a modified natural gum (pine in this study), and to the best of our knowledge, such type of agent is proposed for the first time to prepare a compatibilized biodegradable polymer blend. Two agents are tested, to see the difference in the interaction effect of the maleated rosins when glycerol or pentaerythritol is used for the maleinization reaction (varying structure polarity in the compatibilizer), aiming for an improvement in mechanical performance in both types of multicomponent polymers, while keeping the biodegradation capability for the blends. For representative mechanical measurements, a temperature sweep for dynamic testing allows the determination of the storage and loss moduli as a function of temperature, along with the thermal transitions and useful temperature range of the materials. In addition, stress-strain measurements show the Young's modulus and rupture strength, while measuring the deformation capacity; the flexural properties are included, due to their relevance for some applications. For the structure characterization, the chemical analysis shows the interaction between the components, and by microscopic observation, the differences in polymer-fiber adhesion across the thickness of the composites, and the decrease in phase separation for the blends caused by the maleated rosins, can be confirmed.

Under those circumstances, in this work, a modified natural gum (maleated pine rosin) is tested here in multiple roles: as coupling agent for composites, and as compatibilizer for biodegradable polymer blends, to increase components interaction that cause structural changes, which in turn produce an improvement in the mechanical performance of those materials, while keeping the biodegradation capability.

\section{MATERIALS AND METHODS}

\section{Materials}

Composites. Post-consumer polypropylene from Ecopolímeros (MEXICO) with a density of $0.87 \mathrm{~g} \mathrm{~cm}^{-3}$ and melt flow index of 1.26 $\mathrm{g} / 10 \mathrm{~min}$ was used as polymer matrix. Agave fiber (AF), (A. tequilana Weber var. Azul), which is a discarded fiber from tequila factories, with $210 \mu \mathrm{m}$ average diameter (washed, dried and milled to 65 mesh without further preparation) was used as reinforcing agent. Pine gum (from the forest industry of Jalisco, MEXICO (with acidity number 145 - $155 \mathrm{mg} \mathrm{KOH} \mathrm{g}^{-1}$ ) was used as coupling agent (R), as a source from natural origin; pine maleated resin (Amberyl M-15A (A15)) provided by Polímeros Sintéticos S.A (MEXICO) with acidity number 15 - $26 \mathrm{mg} \mathrm{KOH} \mathrm{g}^{-1}$ was used as $\mathrm{CA}$, maleated polyethylene (Epolene E-43 (E)) provided by Eastman Chemical Corp. (USA) with acidity number of 40 - $55 \mathrm{mg} \mathrm{KOH} \mathrm{g}^{-1}$ was also used as CA.

Polymer blends. PLA grade 2003D (from Nature works LLC, USA), and PBAT (ECOFLEX F blend C1200, from BASF), were used as acquired to prepare the polymer blends. A15 and Amberyl MP-30 (A30), acidity number $15-25 \mathrm{mg} \mathrm{KOH} \mathrm{g}^{-1}$ (both provided by Polímeros Sintéticos S.A. (MEXICO)), were used as compatibilizing agents

\section{Preparation, processing and testing of samples}

Composites. PPr composites with AF were obtained by a two stage process in a twin screw extruder (Leistritz Micro 27 GL/GG 32D) doing AF feeding with a side feeder. The extruder has an $\mathrm{L} / \mathrm{D}=36$ (screw diameter $=27 \mathrm{~mm}$ ). Mixing was done in a corrotative mode (temperature range: $165-190{ }^{\circ} \mathrm{C}$ ). For the first stage, PPr and one CA were extruded to attain a fine CA dispersion. The product was granulated and re-extruded, while adding along the AF (previously dried in a convection oven at $65^{\circ} \mathrm{C}$ for $48 \mathrm{~h}$ ). Composite plates ( 3 $\mathrm{mm}$ of thickness) were prepared in a Carver press at $180{ }^{\circ} \mathrm{C}$ and 49 $\mathrm{kN}$ of closing force.

Compatibilized polymer blends: First, PLA and PBAT were dried at $60{ }^{\circ} \mathrm{C}$ for $48 \mathrm{~h}$. Blends of PLA/PBAT (80/20 w/w) (I), were prepared in the aforementioned twin screw extruder at $160-180$ ${ }^{\circ} \mathrm{C}$, after premixing each blend in manual form with the respective compatibilizer (using 2, 3, 4 or 6 wt $\%$ of A 15 or A30 with respect to the polymer blend weight, in powder form). The extruded materials were dried in an oven at $60{ }^{\circ} \mathrm{C}$ for $48 \mathrm{~h}$ to prepare samples for mechanical tests by injection molding (NISSEI model ES-1000), at $190{ }^{\circ} \mathrm{C}$.

Dynamic-mechanical tests: Dynamic properties of both types of multicomponent polymers as a function of temperature were followed using a dynamic mechanical analyzer of TA Instruments (Model Q800) following ASTM D-5023-01 at a frequency of $1 \mathrm{~Hz}$. For the composites, the temperature test range used was from -40 to $100{ }^{\circ} \mathrm{C}$, and for the polymer blends from -65 to $150{ }^{\circ} \mathrm{C}$.

Static-mechanical testing: For the composites and blends, the stress-strain (ASTM D 638-03 using IV-b type specimens), and flexural tests (ASTM D-790-03), were performed in an Instron Universal Testing Machine (model 4411 ) at $25^{\circ} \mathrm{C}$, using a crosshead speed of 5 and $1 \mathrm{~mm} \mathrm{~min}^{-1}$ respectively (using $50 \mathrm{~mm}$ between bars for the flexural tests).

Attenuated total reflection Fourier transform infrared spectroscopy (ATR-FTIR): Spectra of the polymeric samples were obtained using a Thermo Scientific, Nicolet iS50. The infrared spectra were recorded at a resolution of $4 \mathrm{~cm}^{-1}$ from 4000 to $500 \mathrm{~cm}^{-1}$.

Scanning electron microscopy (SEM): For this characterization, the polymeric materials with and without $\mathrm{CA} /$ compatibilizer were cryogenically fractured in liquid nitrogen before they were gold coated using a vacuum sputter, to observe them (across the thickness) in a TESCAN equipment (model MIRA 3LMU).

Blends Biodegradation: For this test, the IS/ISO20200:2004 norm was applied, using $25 \times 25 \times 2.5 \mathrm{~mm}^{3}$ samples to do composting in a convection oven for 90 days.

\section{Samples Code}

For the discussion in the next section, a code is presented in Tables 1 and 2 for all the polymeric materials used in this work.

Table 1. Polymeric material codes for $\mathrm{PPr} / \mathrm{AF}$ composites and components with/without CA

\begin{tabular}{|c|c|}
\hline Composition & Code \\
\hline Post-consumer PP & $\operatorname{PPr}$ \\
\hline $\mathrm{PPr}+18 \mathrm{wt} \%$ Agave fiber & $18 \mathrm{PPr}$ \\
\hline $\operatorname{PPr}+18 \mathrm{wt} \%$ Agave fiber $+3 \mathrm{wt} \%$ Rosin & 18PPr-R \\
\hline $\mathrm{PPr}+18 \mathrm{wt} \%$ Agave fiber $+3 \mathrm{wt} \%$ Amberyl M-15A & 18PPr-A15 \\
\hline PPr $+18 w t \%$ Agave fiber $+3 w t \%$ Epolene E- 43 & 18PPr-E \\
\hline $\mathrm{PPr}+36 \mathrm{wt} \%$ Agave fiber & $36 \mathrm{PPr}$ \\
\hline $\mathrm{PPr}+36 \mathrm{wt} \%$ Agave fiber $+3 \mathrm{wt} \%$ Rosin & $36 \mathrm{PPr}-\mathrm{R}$ \\
\hline $\mathrm{PPr}+36 \mathrm{wt} \%$ Agave fiber $+3 \mathrm{wt} \%$ Amberyl M-15A & 36PPr-A15 \\
\hline PPr $+36 w t \%$ Agave fiber $+3 w t \%$ Epolene E- 43 & 36PPr-E \\
\hline
\end{tabular}

\section{RESULTS AND DISCUSSION}

\section{Dynamic Mechanical Analysis (DMA)}

DMA results for the composite formulations of PPr reinforced 
Table 2. Polymeric material codes for blends and components with/without CA

\begin{tabular}{cc}
\hline Composition & Code \\
\hline PLA & PLA \\
PBAT & PBAT \\
$80 / 20 \mathrm{w} / \mathrm{w}$ PLA/PBAT & BL \\
$80 / 20 \mathrm{w} / \mathrm{w}$ PLA/PBAT + & BL-A15-2, BL-A15-3, \\
A15 $(2 \mathrm{wt} \%),(3 \mathrm{wt} \%),(4 \mathrm{wt} \%)$ or $(6 \mathrm{wt} \%)$ & BL-A15-4, BL-A15-6 \\
$80 / 20 \mathrm{w} / \mathrm{w}$ PLA/PBAT + A30 $(2 \mathrm{wt} \%)$, & BL-A30-2, BL-A30-3, \\
$(3 \mathrm{wt} \%),(4 \mathrm{wt} \%)$ or $(6 \mathrm{wt} \%)$ & BL-A30-4, BL-A30-6 \\
\hline
\end{tabular}

with 18 or 36 wt $\%$ of $\mathrm{AF}$, containing 3 wt $\%$ of the respective CA, are shown in Figures 1 and 2. There, the composites' response as a function of temperature can be observed to compare the effect of the coupling agents used on such properties. For storage modulus (E'), all composite materials follow similar behavior as temperature increases up to $100{ }^{\circ} \mathrm{C}$.

For the specific composites, in Figure 1a) it can be noticed that the separation in E' trajectory is minimal for the different composites containing $18 \mathrm{wt} \%$ of $\mathrm{AF}$, especially in the low temperature region, and up to $20^{\circ} \mathrm{C}$. At that temperature, $18 \mathrm{PPr}-\mathrm{E}$ and $18 \mathrm{PPr}-\mathrm{A} 15$ materials present the higher E' values and they maintain their position up to $100{ }^{\circ} \mathrm{C}$. The small difference in E' values can be seen in Table 3, denoting that there is only a $6.1 \%$ difference between the highest (18PPr-E) and lowest (18PPr-R) E' value of the coupled composites at $20{ }^{\circ} \mathrm{C}$ with respect to $\mathrm{PPr}$, although the increments in $\mathrm{E}$ ' value are 27.7 and $21.6 \%$, respectively. The small difference in values may be due to the small AF content in the materials. However, for composites with 36 wt \% of AF (Figure 2a)), such type of difference increases to $29 \%$ (between 36 PPr-A15 and 36PPr-E materials), and the equivalent increments in E' correspond to 45.2 and $16.5 \%$ respectively. Both types of coupling agents (the commercial one and the rosin coupling agents) show a positive effect with the low content of fiber, while for the composites with high content, only the rosin agents offered positive results, exhibiting the higher values of E' for the entire temperature range studied (Figure 2a)). Furthermore, looking at Table 3, it is important to notice that both of the rosin coupling agents produce an increase in $\mathrm{E}^{\prime}$ (at $20^{\circ} \mathrm{C}$ ) as the fiber content increases, while for the commercial agent (Epolene E-43) the effect was negative when the fiber content was increased, denoting less interaction between the polymer and the fiber with such agent if a high fiber concentration is used.

For loss modulus (E"), an almost constant value in the low temperature region (Figures $1 b$ ) and $2 b$ )) that coincides with the

a)

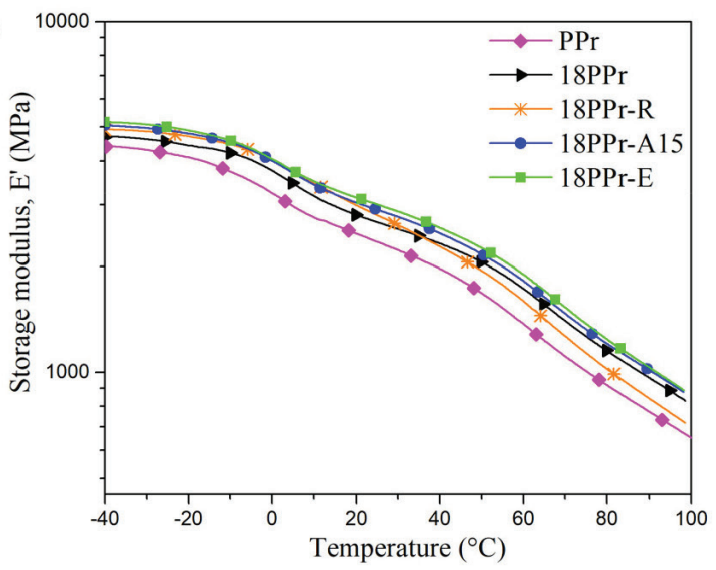

equivalent E' behavior is followed by a peak which represents the PP glass transition temperature of the materials (Table 3); the temperature of such peak corresponds to the small decrease in E' at approximately $0{ }^{\circ} \mathrm{C}$ (Figure 1a)). For the composites, the PP Tg displacement from $-19{ }^{\circ} \mathrm{C}^{23}$ to higher value, is caused by the fiber presence; that behavior has been typically reported with different kinds of reinforcing agents. Additionally, small variations in the peak temperature among the composites can be noticed in Figures $1 b$ ) and $2 b$ ) for samples containing the same amount of AF; those variations appear due to the inclusion of the different CAs used. Such phenomenon is related to the role of a CA, which acts as a link between the polymer and the fiber. The generated forces of attraction promote a retardation of segmental movement within amorphous molecules of the polymer. Such interaction is reflected in the higher E' values obtained with the composites containing rosin, compared to those containing the commercial CA, being the maleated rosin $\mathrm{CA}$ the one which provides the highest reinforcement.

For the PLA/PBAT blends, the dynamic-mechanical results for the 80/20 w/w samples are shown below in Figure 3, varying the concentration of the used rosin compatibilizers. For the E' plots (Figures $3 \mathrm{a}$ ), and 3c)), all blend materials lie in between the trajectories of the pure components (PLA and PBAT); for the blends, the decrease in modulus caused by the PBAT presence is extended by a decrement in the vicinity of its $\mathrm{Tg}$, which appears between -24 and $-20{ }^{\circ} \mathrm{C}$ depending on the wt $\%$ of the compatibilizer used. Then, the E' value of the blends remains almost constant, until the Tg of PLA is approached. Finally, the PLA crystallization in cold ${ }^{24}$ can be noticed in the PLA sample, and all the blend materials, at approximately $100^{\circ} \mathrm{C}$. The positive effect of the maleated rosin compatibilizers on storage modulus of the blends (varying compatibilizer concentration), can be observed in both formulations, showing the A30 compatibilizer the higher effect comparing with the blend without compatibilizer. Looking at Table 4 for the E' values, it can be noticed that the highest increment for the A30 agent, is obtained with $3 \mathrm{wt} \%$ of compatibilizer. Such effect which relies on intermolecular forces of attraction, is temperature dependent, and the attained increments in E' decrease after the glass transition temperature is reached.

The variations in thermal transitions of the polymer blends can be observed in Figures 3b) and 3d), where loss modulus is plotted as a function of temperature. While pure PBAT and PLA respectively show their $\mathrm{Tg}$ at -29.8 and $57.3^{\circ} \mathrm{C}$, the PBAT value is more affected by blending; its value moves to $-26^{\circ} \mathrm{C}$, whereas the PLA value moves only to $56{ }^{\circ} \mathrm{C}$. Likewise, by the addition of the compatibilizers, the PBAT Tg increases more with compatibilizer concentration $\left(6^{\circ} \mathrm{C}\right)$, than what the PLA decreases $\left(3^{\circ} \mathrm{C}\right)$.

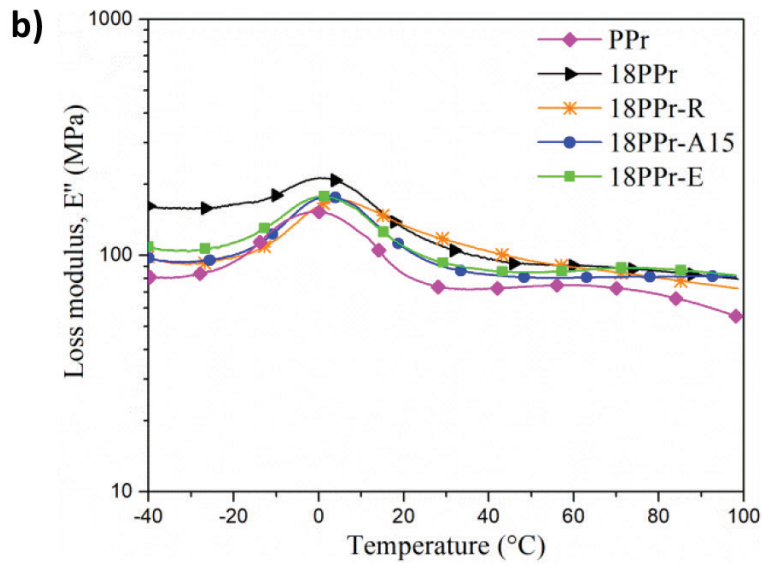

Figure 1. Temperature dependence of PPr and its composites with $18 \mathrm{wt} \%$ of AF, with/without coupling agent for: a) Storage modulus; b) Loss modulus at 1 Hz frequency 
a)

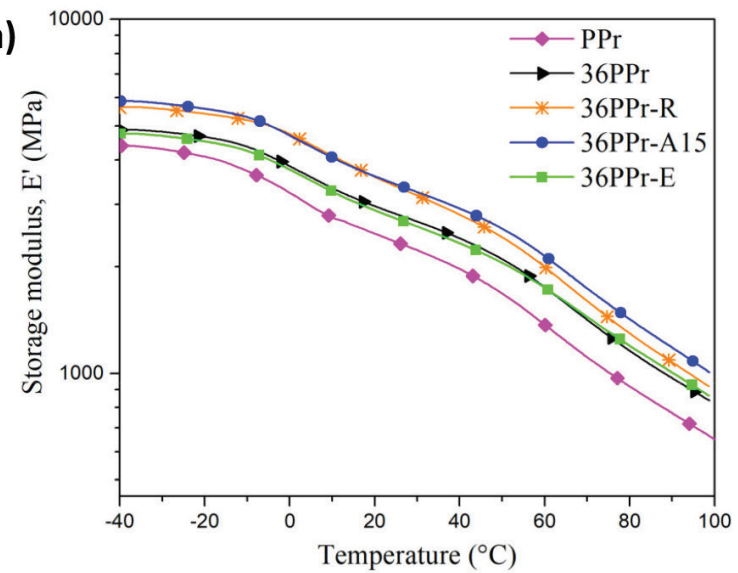

b)

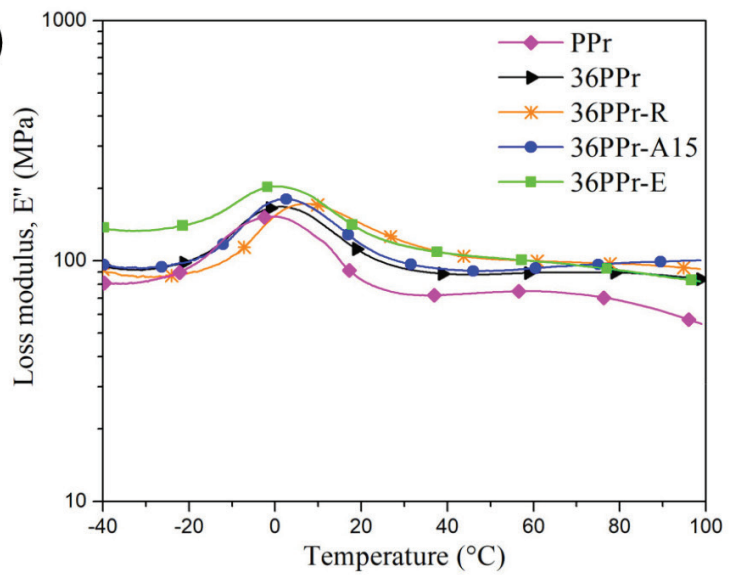

Figure 2. Temperature dependence of PPr and its composites with $36 w t \%$ of AF, with/without coupling agent for: a) Storage modulus; b) Loss modulus at $1 \mathrm{~Hz}$, frequency
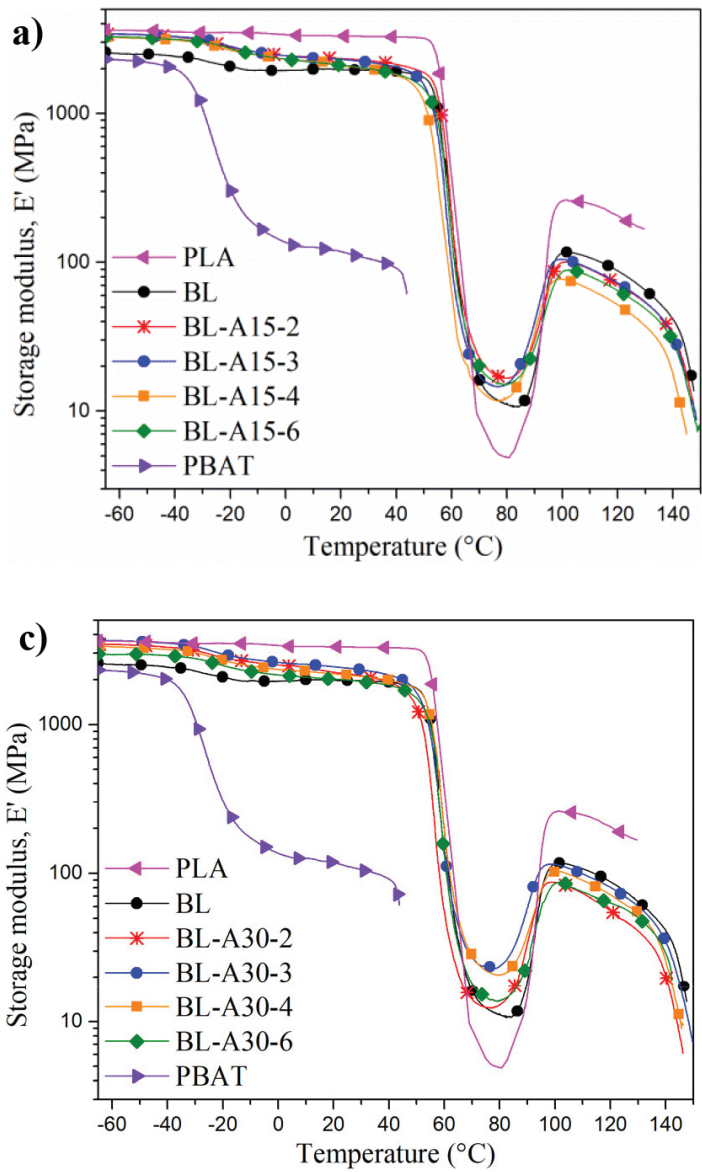
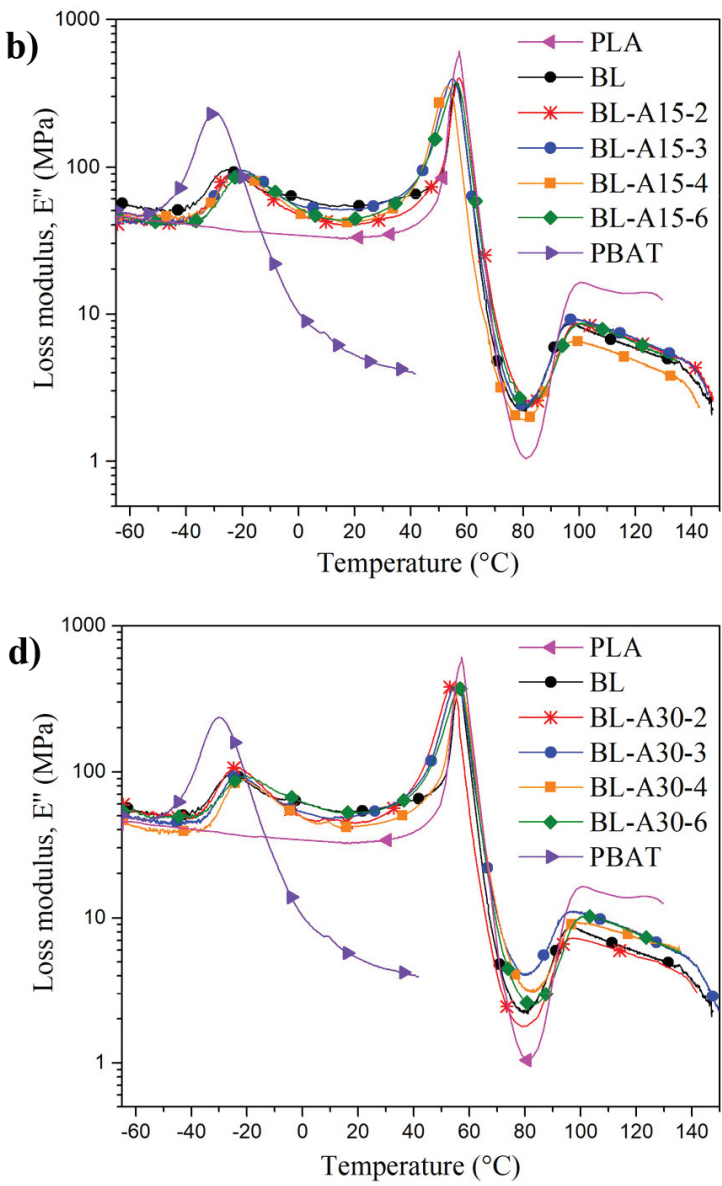

Figure 3. Temperature dependence of PLA, PBAT and 80/20 w/w PLA/PBAT blends, with/without compatibilizer for: a) and c) Storage modulus; b) and d) Loss modulus at $1 \mathrm{~Hz}$ frequency

Such behaviors indicate that the amorphous molecules of PBAT are better able to interact with the compatibilizers than what the PLA molecules do, probably due to the high PLA crystallinity value, ${ }^{25}$ with respect to $\mathrm{PBAT},{ }^{26}$ such morphology promotes rigidity and complicates compatibilizer diffusion between the molecules. Nevertheless, the similar and adjacent trajectories of the blends for E" up to $75^{\circ} \mathrm{C}$, specify small differences in energy dissipation capacity.

\section{Static tests}

All the composites show a higher Young modulus than the PPr
(Table 3). The use of AF without CA produces an increment of 14.9 or $34 \%$ for the composites (with 18 or $36 \mathrm{wt} \%$ of AF respectively); however, with the inclusion of a CA, the effect is magnified. Such increment in modulus rises to $23.3 \%$ using natural rosin with 18 $\mathrm{wt} \%$ of $\mathrm{AF}$, while for composites with high fiber content, the higher increase was obtained with maleated rosin $(61.7 \%)$. Besides the substantial increment in Young modulus of the latter composite, it is also significant that in accordance with dynamic measurements, the effect of the rosin CAs was much higher than the one obtained with Epolene E-43. Such Young modulus value $(771.7 \mathrm{MPa})$ puts that material property (using a post-consumer source) within the range 
of virgin high-density polyethylene values. ${ }^{27}$

For tensile strength, since the property implies a destructive test (stress-strain test up to rupture), the decrement in strength for the composites without CA with respect to PPr, can be attributed to non-uniform fiber dispersion, ${ }^{28}$ and lack of interaction between fiber and polymer; such phenomenon is more noticeable with low fiber content. Nevertheless, the inclusion of the CAs produces a positive effect, causing again the rosin agents the higher increments among the CAs, noticing that the higher increments are obtained with the high $\mathrm{AF}$ content, where using the $\mathrm{A} 15$ agent, the respective increment is 38.1 or $52.6 \%$ comparing to $\mathrm{PPr}$ or to the composite without $\mathrm{CA}$. The notable increments obtained with the A15 rosin in the stress-strain aforementioned parameters (compared to Epolene E-43), also surpassed the values reported by Haq and Srivastava, using maleated PP (MAPP) to compatibilize recycled PP with 50 wt $\%$ of mango fibers. They only obtained approximately $22 \%$ increment for both Young modulus and rupture strength, using $3 \mathrm{wt}$ $\%$ of compatibilizer. ${ }^{29}$ In a former report, Ichazo et al., using virgin PP achieved 8.4 and $16.2 \%$ increments in Young modulus and rupture strength respectively, using 3.45 wt $\%$ of MAPP as compatibilizer with 40 wt $\%$ of wood fiber. ${ }^{30}$

For flexural tests that combine stress and compression, there is a correspondence for the CAs in the effect promoted for moduli values. For the composites with a low amount of fiber, the maleated rosin yields the higher increments; while when using $36 \mathrm{wt} \%$ of fiber, the highest position was for the commercial CA, although the A15 CA also promoted high values (Table 3).

For tensile tests of the PLA/PBAT blends, the results are shown in Table 4, varying the concentration of the two maleated rosin agents used. The pure polymeric materials circumscribe the properties values of all the blends; the equivalent blends for the different compatibilizers show very slight differences in Young modulus, but certain variations in yield stress appear, depending on the rosin concentration. The deformation capacity contribution of the PBAT is positively reflected with both compatibilizers. Specific values of the mentioned properties can be seen in Table 4, where it can be noticed in general, that for Young modulus and yield stress, the blends with 3 wt $\%$ of compatibilizer show the best results for both types of agents, obtaining higher values using A30. For deformation capacity, the fact that blends containing $20 \mathrm{wt} \%$ of PBAT yield an improved toughness performance is related to its low Tg (Figures $3 \mathrm{~b}$ ) and 3 d)), although PLA and PBAT polymers have the tendency to present phase separation. Kumar et al. demonstrated this situation in the PLA/ PBAT system by scanning electron microscopy, and observed the effect of a glycidyl methacrylate as compatibilizer to diminish phase separation, testing mechanical properties of blends with $15-25$ wt \% of PBAT.22 That explains why, the deformation capacity is increased with compatibilizer concentration (as it is shown in this work, Table 4). Such behavior is also in agreement with the work of Zhao et al. ${ }^{31}$ who reported that the deformation capacity of PLA/PBAT blends increases with PBAT concentration up to $15 \mathrm{wt} . \%$; showing a decrease at higher concentrations. For flexural behavior, modulus and strength of the blends present an increase with the inclusion of the compatibilizer, showing in general the best results with $3 \mathrm{wt} \%$ of agent (Table 4), with slightly higher values using A30.

\section{Infrared analysis of materials composition (ATR-FTIR)}

The interactions generating hydrogen bonding between the CAs and the composite components (to improve mechanical performance) are depicted in Figure 4a), where FTIR spectra of all composites with 36 wt $\%$ of AF for the different coupling agents show the decrease of the $\mathrm{C}-\mathrm{H}$ absorbance peak in the $1455-1375$ wave number range $\mathrm{e}^{32}$ in the methoxy group of the coupled composites, with respect to the composite without CA. Likewise, the decrease of the absorbance peak in the ester group (-COO-R) within the 1200-1120 range for the coupled composites compared to the composite without $\mathrm{CA}$ can also be seen there.

For the compatibilized PLA/PBAT 80/20 w/w blends with A30 (Figure 4b)), the decreasing correspondent peak appears at the 3000-2800 range, where it can be noticed that the $-\mathrm{CH}_{2}$ peak shows a maximum shrinkage between 3 and 4 wt $\%$ of A30 (showing the hydrogen bond variations with respect to the pure blend); such type of effect was reflected in mechanical performance. The hydrogen bonding linkage detection by FTIR between the components reported here has also been applied in PP composites reinforced with natural fibers. N. Hamour et al. reported such type of interaction using alfa fiber as reinforcement, achieving the coupling with MAPP; ${ }^{33}$ likewise, N. I. Zulkifli et al. detected the interactions between PPr, MAPP and microcrystalline cellulose that caused improvement in tensile modulus depending on fiber concentration. ${ }^{34}$

\section{Microscopy}

SEM photographs in Figure 5 allow the observation of the differences in morphology that arise in PPr composites with the inclusion of a CA. For the composite with $36 \mathrm{wt} \%$ of AF without CA (Figure 5a)), a separation between a non-deformed fiber and the polymer surface can be noticed, along with a hole with a flat or even surface. Conversely, for the photographs of composites with CA, more stratified surfaces can be observed (images $5 b)-5 d$ ) in Figure 5), along with embedded, deformed and/or corrugated

Table 3. Mechanical properties of $\mathrm{PPr}$ and $\mathrm{PPr} / \mathrm{AF}$ composites with/without CA

\begin{tabular}{|c|c|c|c|c|c|c|}
\hline $\begin{array}{l}\text { Polymeric material } \\
\text { code }\end{array}$ & $\begin{array}{l}\text { Young Modulus } \\
\text { (MPa) }\end{array}$ & $\begin{array}{l}\text { Tensile strength } \\
\text { (MPa) }\end{array}$ & $\begin{array}{l}\text { Flexural modulus } \\
\qquad(\mathrm{MPa})\end{array}$ & $\begin{array}{l}\text { Flexural strength } \\
\quad(\mathrm{MPa})\end{array}$ & $\begin{array}{l}\text { Storage modulus, } \\
\text { E' (MPa) } \\
20^{\circ} \mathrm{C}\end{array}$ & $\mathrm{Tg}$ from $\mathrm{E} "\left({ }^{\circ} \mathrm{C}\right)$ \\
\hline PPr & $477.1 \pm 24.1$ & $4.22 \pm 0.2$ & $581.4 \pm 31.2$ & $11.23 \pm 0.5$ & 2480.4 & -0.5 \\
\hline $18 \mathrm{PPr}$ & $548.3 \pm 30.3$ & $2.91 \pm 0.3$ & $929.8 \pm 39.9$ & $13.97 \pm 0.5$ & 2804.6 & 0.2 \\
\hline 18PPr-R & $588.3 \pm 28.1$ & $4.14 \pm 0.3$ & $918.7 \pm 41.5$ & $10.91 \pm 0.7$ & 3015.6 & 4.4 \\
\hline 18PPr-A15 & $576.4 \pm 31.3$ & $3.41 \pm 0.3$ & $1186.9 \pm 43.2$ & $18.13 \pm 0.9$ & 3070.0 & 1.7 \\
\hline $18 \operatorname{PPr}-\mathrm{E}$ & $583.5 \pm 17.8$ & $3.93 \pm 0.2$ & $1062.9 \pm 48.2$ & $14.82 \pm 0.8$ & 3168.0 & 1.2 \\
\hline $36 \mathrm{PPr}$ & $639.1 \pm 23.7$ & $3.82 \pm 0.3$ & $1258.5 \pm 53.8$ & $15.30 \pm 1.1$ & 2966.7 & 1.4 \\
\hline 36PPr-R & $652.8 \pm 33.1$ & $3.93 \pm 0.4$ & $1606.2 \pm 48.3$ & $20.42 \pm 1.0$ & 3592.3 & 5.8 \\
\hline 36PPr-A15 & $771.7 \pm 12.1$ & $5.81 \pm 0.3$ & $1676.1 \pm 45.4$ & $23.40 \pm 1.0$ & 3600.0 & 2.4 \\
\hline $36 \operatorname{PPr}-\mathrm{E}$ & $669.2 \pm 37.0$ & $5.54 \pm 0.2$ & $1707.7 \pm 49.6$ & $26.54 \pm 0.7$ & 2889.4 & 0.3 \\
\hline
\end{tabular}


Table 4. Mechanical properties of PLA, PBAT and 80/20 w/w PLA/PBAT blends with/without compatibilizer

\begin{tabular}{|c|c|c|c|c|c|c|c|c|}
\hline $\begin{array}{l}\text { Polymeric } \\
\text { material code }\end{array}$ & $\begin{array}{l}\text { Young } \\
\text { Modulus } \\
(\mathrm{MPa}) \\
\end{array}$ & $\begin{array}{l}\text { Yield stress and } \\
\text { Tensile strength } \\
\text { (MPa) } \\
\end{array}$ & $\begin{array}{l}\text { Deformation } \\
\text { at break }(\%)\end{array}$ & $\begin{array}{l}\text { Flexural modulus } \\
\qquad(\mathrm{MPa})\end{array}$ & $\begin{array}{c}\text { Flexural } \\
\text { strength (MPa) }\end{array}$ & $\begin{array}{c}\text { Storage modulus, } \\
\mathrm{E}^{\prime}(\mathrm{MPa}) \\
20^{\circ} \mathrm{C} \\
\end{array}$ & $\begin{array}{l}\text { Tg from E" } \\
\text { for PBAT } \\
\left({ }^{\circ} \mathrm{C}\right) \\
\end{array}$ & $\begin{array}{l}\text { Tg from E" } \\
\text { for PLA } \\
\left({ }^{\circ} \mathrm{C}\right)\end{array}$ \\
\hline PLA & $1543.6 \pm 11.4$ & $\begin{array}{l}63.05 \pm 2.1 \\
63.05 \pm 0.8 \\
\end{array}$ & $5.46 \pm 0.2$ & $3500.6 \pm 48.1$ & $101.68 \pm 2.9$ & 3322.9 & - & 57.3 \\
\hline PBAT & $42.8 \pm 0.4$ & $\begin{array}{c}7.41 \pm 0.6 \\
19.23 \pm 0.5\end{array}$ & $1180.2 \pm 2.9$ & - & - & 118.5 & -29.8 & - \\
\hline $\mathrm{BL}$ & $1166.8 \pm 7.4$ & $\begin{array}{l}45.03 \pm 0.8 \\
27.37 \pm 0.4 \\
\end{array}$ & $56.37 \pm 7.7$ & $2549.5 \pm 22.2$ & $69.61 \pm 1.5$ & 1979.5 & -25.6 & 56.3 \\
\hline BL-A15-2 & $1144.9 \pm 7.5$ & $\begin{array}{l}45.83 \pm 0.1 \\
25.42 \pm 0.5\end{array}$ & $31.36 \pm 3.9$ & $2384.7 \pm 29.4$ & $69.51 \pm 1.7$ & 2344.2 & -22.9 & 57.2 \\
\hline BL-A15-3 & $1235.8 \pm 12.5$ & $\begin{array}{l}50.87 \pm 0.6 \\
30.16 \pm 0.7\end{array}$ & $47.74 \pm 2.5$ & $2576.3 \pm 59.7$ & $73.14 \pm 1.7$ & 2320.6 & -21.0 & 54.8 \\
\hline BL-A15-4 & $1167.2 \pm 13.2$ & $\begin{array}{l}48.11 \pm 1.4 \\
27.76 \pm 0.9 \\
\end{array}$ & $46.34 \pm 3.0$ & $2575.4 \pm 19.1$ & $73.76 \pm 1.2$ & 2087.3 & -21.9 & 53.1 \\
\hline BL-A15-6 & $1164.2 \pm 13.5$ & $\begin{array}{l}45.77 \pm 0.6 \\
26.17 \pm 0.7 \\
\end{array}$ & $55.89 \pm 5.5$ & $2663.3 \pm 19.7$ & $74.79 \pm 0.5$ & 2118.9 & -19.7 & 56.2 \\
\hline BL-A30-2 & $1181.6 \pm 3.5$ & $\begin{array}{l}47.46 \pm 0.6 \\
27.98 \pm 1.0 \\
\end{array}$ & $47.46 \pm 0.6$ & $2549.8 \pm 35.0$ & $74.51 \pm 1.1$ & 2252.0 & -23.7 & 53.4 \\
\hline BL-A30-3 & $1238.4 \pm 5.7$ & $\begin{array}{l}52.52 \pm 0.6 \\
30.94 \pm 0.9 \\
\end{array}$ & $42.58 \pm 1.3$ & $2855.1 \pm 58.7$ & $79.80 \pm 2.9$ & 2442.4 & -23.1 & 55.3 \\
\hline BL-A30-4 & $1219.8 \pm 18.4$ & $\begin{array}{l}47.56 \pm 1.3 \\
27.87 \pm 0.8 \\
\end{array}$ & $47.20 \pm 0.8$ & $2641.8 \pm 13.1$ & $74.82 \pm 0.4$ & 2185.2 & -21.8 & 57.0 \\
\hline BL-A30-6 & $1176.6 \pm 9.9$ & $\begin{array}{l}47.46 \pm 0.4 \\
25.81 \pm 1.0\end{array}$ & $52.17 \pm 6.1$ & $2668.0 \pm 31.3$ & $75.46 \pm 0.3$ & 2021.2 & -20.2 & 56.2 \\
\hline
\end{tabular}
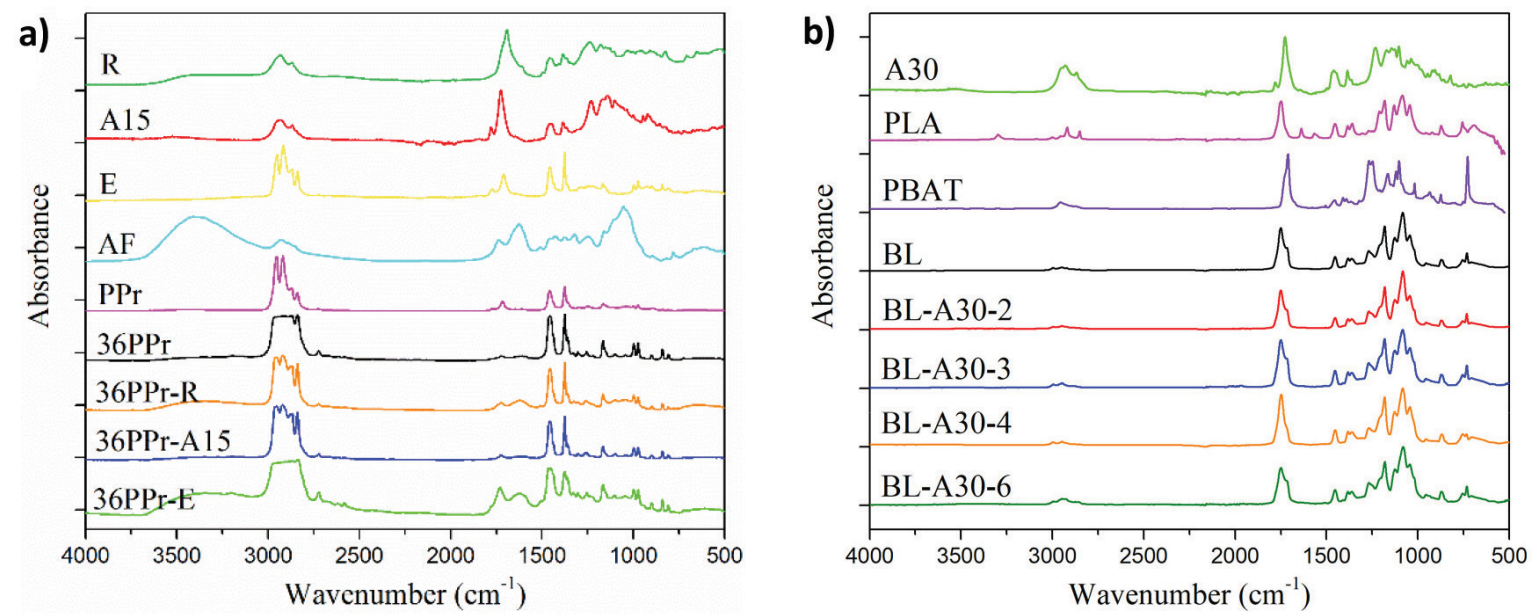

Figure 4. ATR-FTIR of: a) PPr, AF, R, A15, E and PPr/AF composites with 36 wt \% AF varying CA type; b) PLA, PBAT, A30 and their blends, varying A30 concentration

fibers, as a result of the polymer-fiber interaction promoted by the CA. Similar observations were reported by Naghmouchi et al. for PP reinforced with lignocellulosic fillers prepared by injection molding. ${ }^{35}$ Here, for the A15 role, the longitudinal fiber fractures that occur indicate adhesion between the fibers and the polymer matrix (supported by the A15 CA). Such adhesion is reflected in the mechanical behavior of the composites, which surpassed the one obtained using Epolene E-43.

In Figure 6a) - 6d) SEM photographs of PLA/PBAT blends allow the morphological observation of how the surface of the biodegradable polymeric materials changes when the concentration of the compatibilizing agent (A30) varies from 0 to $4 \mathrm{wt} \%$. In Figure 6a) without compatibilizer, a dispersed phase (PBAT) can be noticed in the polymer matrix (PLA) as spherical domains. They decrease in size depending on the compatibilizer concentration showing a maximum decrease at 3 wt $\%$ of A30 (Figure 6c)). For the correlation of domain size and global mechanical performance, it can be stated that here the optimum concentration is $3 \mathrm{wt} \%$, since it generally yields the best dynamic and tensile behavior among the blends, with the A30 agent being the one that offers the best results. The situation of the optimum phase separation for two component blends has been stated in terms of finding an optimum contribution of each component, which occurs between components miscibility (which leads to a simple weighted performance), and macrophase separation (which leads to absence of interaction with poor performance). The results obtained here confirm the benefit of a limited reduction in domain size at microphase level, because an excessive reduction leads to a decrease in the contribution of the dispersed phase. Such phenomenon was reported time ago for blends ${ }^{36}$ and interpenetrating polymer networks, ${ }^{37,38}$ and recently for copolymers also looking for synergic mechanical performance..$^{39,40}$ 
a)

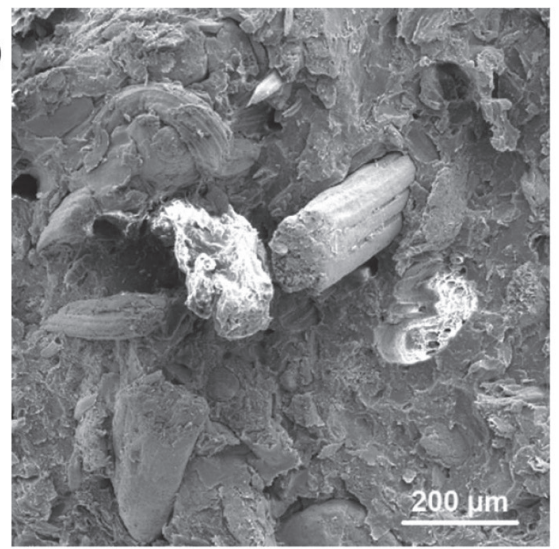

c)

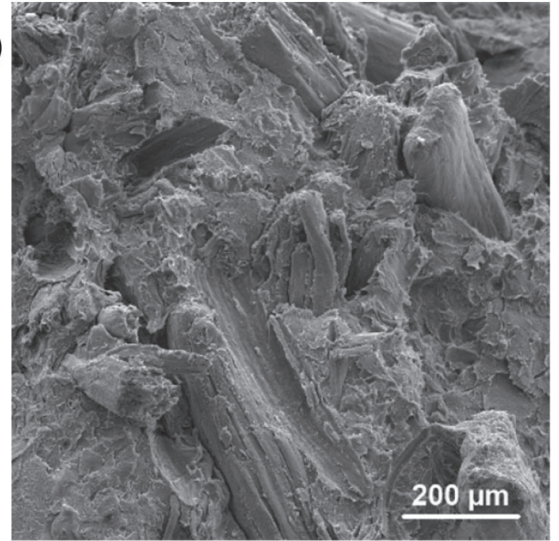

b)

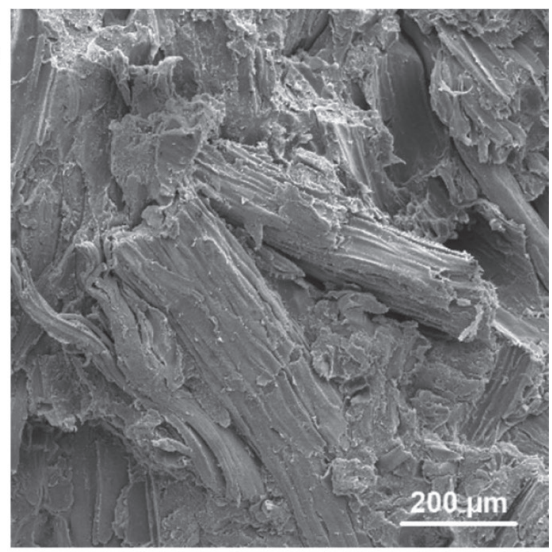

d)

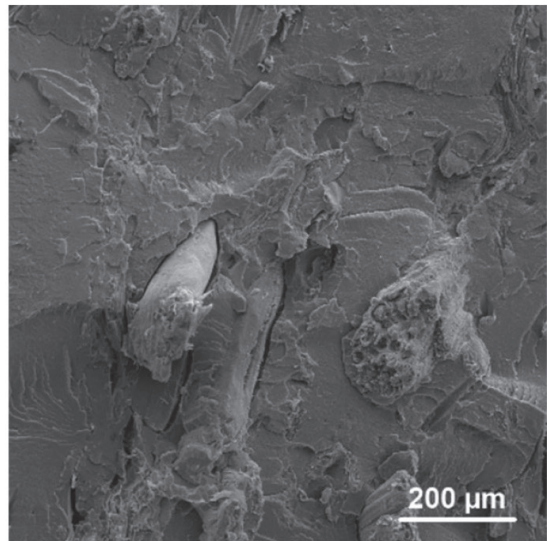

Figure 5. SEM photographs of PPr composites with $36 \%$ of AF for: a) composite without coupling agent; b) composite with $3 w t \% R$ as CA; c) composite with 3 wt \% of A15 as CA; d) composite with $3 w t \%$ of $E$ as $C A$

a)

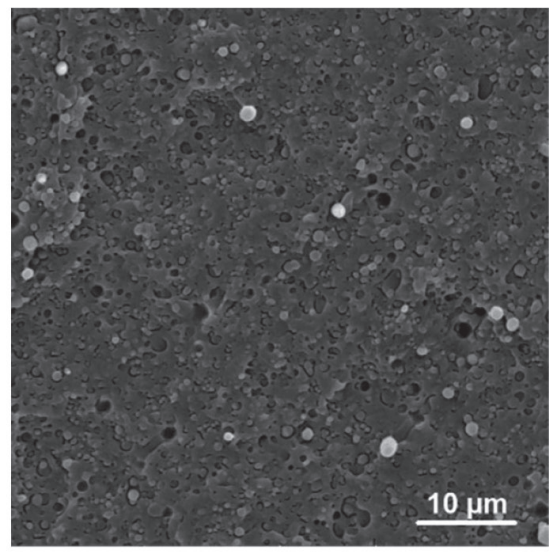

c)

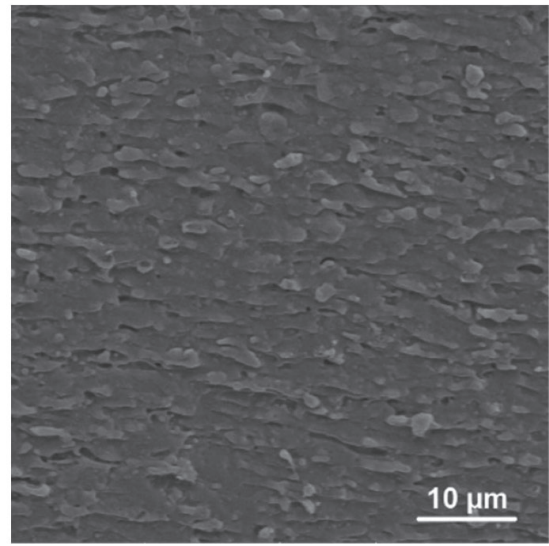

b)

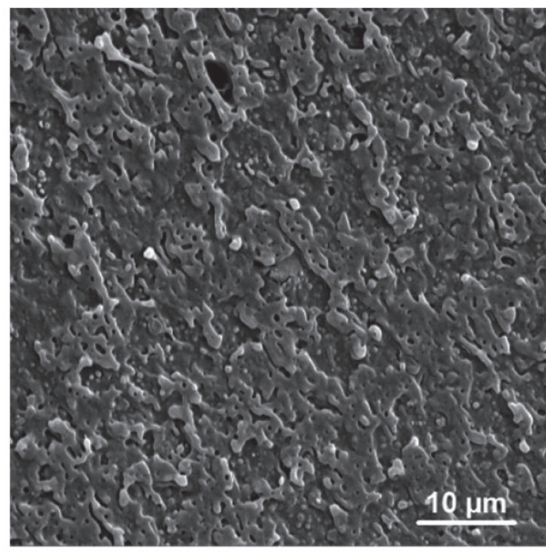

d)

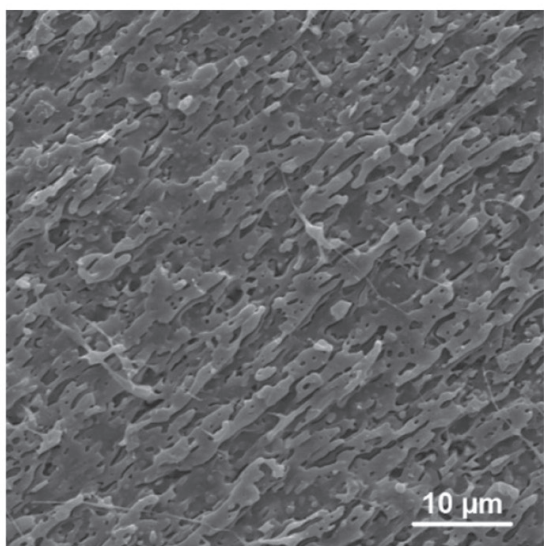

Figure 6. SEM photographs of 80/20 w/w PLA/PBAT blends for: a) blend without compatibilizer; b) blend with 2 wt \% of A30; c) blend with 3 wt $\%$ of A30; d) blend with 4 wt \% of $A 30$ 


\section{Biodegradation}

For biodegradable behavior (Table 5), the weight loss results as a function of time are positive for the tested materials. For the 90day period of the experimental test, the values obtained for PLA and the different blends present certain variation, achieving the highest degradation rate for PLA and the lowest for PBAT; nevertheless, reasonable biodegradation values were obtained for the blends that included compatibilizer, indicating that the help that it can afford to improve mechanical performance, does not affect its biodegradation capability. Furthermore, extrapolating the data of Table 5 for the blends residual weight to $0 \%$, the time values are 107 and 128 days for the blends with A30 and A15 respectively. Such values are shorter than the one indicated by the European standard for biodegradability of materials (180 days), using composting.$^{41}$ The biodegradation capability of blends is becoming an important issue for specific applications, and the maleinization or similar modifications of natural gums (like pine rosin) may be used to increase chemical component interactions.

Table 5. Residual weight as a function of time for PLA and 80/20 w/w PLA/ PBAT blends by composting with/without compatibilizer

\begin{tabular}{lccccc}
\hline $\begin{array}{l}\text { Polymeric } \\
\text { material } \\
\text { code }\end{array}$ & 15 days & 30 days & 45 days & 60 days & 90 days \\
\cline { 2 - 6 } & 74.9 & 44.7 & 25.5 & 9.0 & 0.0 \\
\hline PLA & 98.4 & 95.3 & 91.0 & 86.9 & 79.3 \\
PBAT & 82.9 & 55.4 & 34.1 & 19.5 & 16.6 \\
BL & 82.2 & 60.4 & 53.7 & 49.6 & 26.4 \\
BL-A15-3 & 78.4 & 62.6 & 32.0 & 25.8 & 23.7 \\
BL-A30-3 & & &
\end{tabular}

\section{CONCLUSIONS}

For the mechanical properties in general, the inclusion of the proposed coupling agents/compatilizers produced increments in storage, Young and flexural moduli and strength (with respect to the correspondent material without agent) for the tested composites and polymer blends. The positive results with such maleated rosins varied with their concentration, establishing an optimum value of 3 wt $\%$ for these systems, as it was demonstrated in the results obtained with polymer blends.

For the PP composites, the maleated rosin agent led to the best overall results; and comparing the two types of maleated rosins used as compatibilizers, the better results were obtained with the more polar one (A30).

For the blends, the results show that the decrease in rigidity of the matrix (PLA), by the inclusion of PBAT, allowed an increase in elastic deformation (to improve toughness), opening the field for the optimization of tough biodegradable polymer blends, maintaining biodegradability with compatibilizers like the ones presented here.

The chemical interaction detected by FTIR demonstrated the $\mathrm{CA} /$ compatibilizing roles of the maleated rosins for the PPr/AF with CA or PLA/PBAT. SEM results confirmed that the interfacial adhesion between polymer matrix and AF using the rosin CAs was active throughout the thickness of the composites. For the blends, SEM photographs showed the decrease in size of the dispersed phase (PBAT particles) in the PLA matrix as the concentration of the compatibilizers increased.

Thus, this work confirms that resins from natural origin in their pure or maleated form can be used as CAs/compatibilizers to improve performance of composites/blends, and opens the field for the exploration of different chemical modifications that may be useful to prepare more efficient coupling agents or compatibilizers for the formulation of biodegradable blends toward environmentally friendly multicomponent polymer products.

\section{SUPPLEMENTARY MATERIAL}

The infrared spectral data are presented in the following link: ht tps://drive.google.com/open?id=1X9qDiTN qmR8IrnJ2n5VyhyLDAGjrnVf

\section{ACKNOWLEDGMENTS}

The authors wish to thank CONACYT and Universidad de Guadalajara for the financial support. J. D. Inga-Lafebre thanks CONACYT for the granted $\mathrm{PhD}$ scholarship.

\section{REFERENCES}

1. Yadav, B. K.; Gidwani, B.; Vyas, A.; J. Bioact. Compat. Polym. 2016, $31,111$.

2. Jasso-Gastinel, C. F.; Pulido, H.; Hernández, M.; Rabelero, M.; Patent Application No. MX/A/2015/002586, 2015.

3. Flowers, B. In Handbook of polypropylene and polypropylene composites; Karian, H. G., ed.; Marcel Dekker: Whitmore Lake, 2003, chap. 17.

4. Guerrica-Echevarría, G.; Eguiazábal, J. I.; Nazábal, J.; Polym. Degrad. Stab. 1996, 53,1.

5. Aurrekoetxea, J.; Sarrionandia, M.A.; Urrutibeascoa, I.; Maspoch, M.; J. Mater. Sci. 2001, 36, 2607.

6. Bahlouli, N.; Pessey, D.; Raveyre, C.; Guillet, J.; Ahzi, S.; Dahoun, A.; Hiver, J. M.; Mater. Des. 2012, 33, 451.

7. Das, K.; Ray, D.; Adhikary, K.; Bandyopadhyay, N. R.; Mohanty, A. K.; Misra, M.; J. Reinf. Plast. Compos. 2010, 29, 510.

8. Pickering, K. L.; Efendy, M. G.; Le, T. M.; Composites, Part A 2016, 83, 98.

9. Jasso-Gastinel, C. F.; Lopez-Carrillo, P.; Mendizabal-Mijares, E.; Polym. Eng. Sci. 1992, 3, 443

10. Maya, J.; Sabu, T.; Varughese, K. T.; Compos. Sci. Technol. 2004, 64, 955.

11. Nabi, D.; Jog, J. P.; Adv. Polym. Technol. 1999, 18, 351.

12. López-Bañuelos, R. H.; Moscoso, F. J.; Ortega-Gudiño, P.; Mendizabal, E.; Rodriguez, D.; González-Núñez, R.; Polym. Eng. Sci. 2006, 52, 2489.

13. Jasso-Gastinel, C. F.; Sanjuan, R.; Mendizabal, E.; Conference proceedings of the 52nd Annual Technical Conference ANTEC 94; San Francisco, United States, 1994.

14. Lila, M. K.; Saini, G. K.; Kannan, M.; Singh, I.; Fibers Polym. 2017, 18 , 806.

15. Li, X.; Tabil, L. G.; Panigrahi, S.; J. Polym. Environ. 2007, 15, 25.

16. Kim, H. S.; Lee, B. H.; Choi, S. W.; Kim, S.; Kim, H. J.; Composites, Part A 2007, 38, 1473.

17. Franco-Marquès, E.; Méndez, J. A.; Pèlach, M. A.; Vilaseca, F.; Bayer, J.; Chem. Eng. J. 2011, 166, 1170.

18. Rydz, J.; Musioł, M.; Zawidlak-Węgrzyńska, B.; Sikorska, W.; In Handbook of Food Bioengineering; Grumezescu, A. M., Holban, A. M., eds.; Academic Press: London, 2018, chap. 14.

19. Ikada, Y.; Tsuji, H.; Macromol. Rapid Commun. 2000, 21, 117.

20. Arrieta, M. P.; Fortunati, E.; Dominici, F.; Rayón, E.; López, J.; Kenny, J. M.; Polym. Degrad. Stab. 2014, 107, 139.

21. Zhang, B.; Bian, X.; Zhou, D.; Feng, L.; Li, G.; Chen, X.; RSC Adv. 2016, 6, 113366.

22. Kumar, M.; Mohanty, S.; Nayak, S. K.; Rahail, M.; Bioresour. Technol. 2010, $101,8406$. 
23. Kissel, W. J.; Han, J. H.; Meyer, J. A.; In Handbook of polypropylene and polypropylene composites; Karian, H. G., ed.; Marcel Dekker: Whitmore Lake, 2003, chap. 2.

24. Lin, S.; Guo, W.; Chen, C.; Ma, J.; Wang, B.; Mater. Des. 2012, 36, 604.

25. Yu, T.; Li, Y.; Composites, Part A 2014, 58, 24.

26. Cardoso, L.; Magaton, M.; Suman, R.; Massayoshi, M.; Polym. Test. 2015, 43, 27.

27. Zhu, L.; Chiu, F.; Fu, Q.; Quirk, R. P.; Cheng, S. Z.; In Polymer Handbook; Brandrup, J., Immergut, E. H., Grulke, E. A., eds.; John Wiley and Sons: New York, 1990, chap. 5.

28. Akil, H. M.; Omar, M. F.; Mazuki, A.; Safiee, S.; Ishak, Z.; Abu, A.; Mater. Des. 2011, 32, 4107

29. Haq, S.; Srivastava, R.; J. Polym. Environ. 2017, 25, 640.

30. Ichazo, M. N.; Albano, C.; González, J.; Perera, R.; Candal, M. V.; Compos. Struct. 2001, 54, 207.

31. Zhao, P.; Liu, W.; Wu, Q.; Ren, J.; J. Nanomater. 2010, 2010, 1.

32. Parker, F.; Applications of infrared spectroscopy in biochemistry, biology, and medicine, Plenum Press: New York, 1971.

33. Hamour, N.; Boukerrou, A.; Bourmaud, A.; Djidjelli, H. Grohens, Y.; Cellul. Chem. Technol. 2016, 50, 1069.
34. Zulkifli, N. I.; Samat, N.; Anuar, H.; Zainuddin, N.; Mater. Des. 2015, $69,114$.

35. Naghmouchi, I.; Espinach, F.; Mutjé, P.; Boufi, S.; Mater. Des. 2015, 65, 454.

36. Rosen, S. L.; Polym. Eng. Sci. 1967, 7, 115

37. Jasso-Gastinel, C. F. In Modification of Polymer Properties; JassoGastinel, C. F., Kenny, J. M., eds.; Elsevier: Oxford, 2017, chap. 8.

38. Lipatov, Y. S. In Interpenetrating Polymer Networks; Klempner, D., Sperling, L. H., Utracki, L. A., eds.; American Chemical Society: Washington, DC, 1994, chap. 4

39. Jasso-Gastinel, C. F. In Encyclopedia of Biomedical Polymers and Polymeric Biomaterials; Mishra, M., ed.; Taylor and Francis: New York, 2015, vol 11

40. Jasso-Gastinel, C. F.; Arnez-Prado, A. H.; Aranda-García, F. J.; SahagúnAguilar, L. O.; López-Dellamary, F. A.; Hernández-Hernández, M. E.; González-Ortiz, L. J.; Polymers 2017, 9, 1.

41. EN 13432: Packaging - Requirements for packaging recoverable through composting and biodegradation-test scheme and evaluation criteria for the final acceptance of packaging; European Standard, 2000. 